\title{
Sensor Data Analysis On Monitoring And Control System Of Temperature And Humidity Based On Android In Soybean Seed Storage Room Using Nodemcu
}

\author{
Sindung HW Sasono ${ }^{1}$ Sri Kusumastuti ${ }^{1}$, Eko Supriyanto ${ }^{1}$, Intan Desika Putri ${ }^{1}$ \\ ${ }^{1}$ Electrical Engineering Dept, Politeknik Negeri Semarang \\ ssindung@gmail.com
}

Abstract- soybean seeds may be damaged during storage time. Temperature and humidity of soybean seed storage room, is one of the external factors of damage to the seed. The system consists of monitoring and control temperature and humidity in some rooms used as soybean seed storage room samples. This study discusses and perform sensor data analysis using several types of temperature and humidity sensors based on Internet of Things. Sensor nodes generate data and processed by a microcontroller NodeMCU ESP8266, and the results data is then transmitted by the Internet network using MQTT broker and stored in the database. Results data is then analyzed to monitor the condition of soybean seed storage room. SHT30 sensor has the most excellent temperature accuracy of $98,21 \%$. DHT22 sensor has the most excellent moisture accuracy of $95.74 \%$. Data sending to the database has a good level of dataloss category for node 1 is $3.39 \%, 4.33 \%$ for node 2 , and $3.22 \%$ for node 3 . Air conditioner control system using Android can keep the room temperature state in the range of $18-230 \mathrm{C}$ and humidity of $40-60 \%$ with an air conditioning remote control setting at $200 \mathrm{C}$ on an area of $36 \mathrm{~m} 2$.

Index Terms- Air Conditioner, Soybean Seeds, MQTT, NodeMCU ESP8266, Temperature and Humidity Sensor

\section{INTRODUCTION}

In the group of foods, soybean is the third most important commodity after rice and corns. Based on data from the Central Bureau of Statistics reported in the Bulletin of Foreign Trade Statistics Import period from March to April, 2017, the imports of soybean in Indonesia is as much as 207.8 thousand tons with a value of US\$ 92.6 million in March 2017, and in the month of April 2017 the volume increased to 242.2 thousand tons which is worth to US\$ 108.0 million. Based on the country of origin, Indonesia is the biggest soybean importer from United States with 238.8 thousand tons which is equivalent to US \$ 106.4 million. The Ministry of Agriculture itself targeted by 2018 , Indonesia to run the soybean self-sufficiency.

One of the limiting factors of soybean production in Indonesia as a tropical region is the rapid decline of the seed during storage time which reduce the supply of high quality seeds. Factors that affect the quality of the seed during storage time is divided into internal and external factors. Internal factors include a genetic trait, the growing power and vigor, skin conditions and initial seed moisture content. External factors such as the packaging of seeds, gas composition, temperature and humidity of the storage room (Copeland and Donald, 1985).

The temperature and humidity of the storage room is one of the external factors that affect the quality of soybean seed. All this time soybean farmers are still give less attention to the temperature and humidity of storage room as one of the important factors for maintaining seed quality. Thus it is necessary for other method to minimize soybean seed damage due to the temperature and humidity mismatch with the monitoring and control effort of storage room.

To solved the problem, then built a system of monitoring and control soybean seed storage space based on IoT (Internet of Things). The system can detect and control the temperature and humidity conditions of the room using a sensor, wherein the data received from the sensors is sent via multiple nodes which are connected to the Internet. The conditions of temperature and humidity of the room can be displayed on the smartphone and also send control commands as a medium of air conditioner control of the room. It is expected that with this system can reduce the damage to soybean seed due to the temperature and humidity of storage space that is not appropriate.

\section{RELATED RESEARCH}

Information technology has undergone a variety of develoment, not only using personal computer but have started using mobile devices, one of which is smartphone. Android is an operating systemthat is used by the smartphone that is open source, so it can be created and developed by the user as needed. Android application is used to monitor and control (Control and Monitoring) of the air conditioner (AC). The results of the research is a system of monitors and temperature controllers based on microcontroller AVR Atmega 16 which able to connect 
with the Internet and can be accessed through the Android smartphone app. (HW Sindung Sasono, Rofi Al Akrom, Rochmat Machmod S, 2015).

Room temperature monitoring system through the Internet (Internet of Things) is a system that utilizes the existing Internet network for monitoring the temperature in a room from a distance or from a different place. The purpose of this study is to design, build and test the sensor node using ESP8266 to measure, record and display data via Web pages. (Ufo Mohammed Mustafa, 2015) In the study just conducted a monitoring system that has not been packaged into an application on the smartphone, as well as have not been able to control the temperature and humidity of the room remotely.

Under the system that has been made and described it in this study, the authors designed a system of monitoring and control of temperature and humidity of the room remotely on some sample room to observe the conditions of temperature and humidity in real time via Android smartphones that have been linked with several sensor nodes. The microcontroller used in the monitoring and control is NodeMCU ESP8266.

\section{SYSTEM DESCRIPTION}

In this research, built a temperature and humidity monitoring and controlling system of the storage room based on Internet of Things. The system uses three sensor nodes that transmit data from the humidity and temperature sensor reading and one node to control air conditioner.

4.

The monitoring system will be built using a 3 sensor nodes, each of which consists of NodeMCU ESP8266, DHT11 sensor, DHT22 sensor, and the sensor SHT30. Sensor nodes are then connected to $\mathrm{Wi}-\mathrm{Fi}$ to be able to connect to the internet. Each node that has been installed with sensors then transmit sensor readings via the Internet using MQTT broker.

5.

The results of sensor data can then be viewed on a android device that has been connected to MQTT broker to do the monitoring. MQTT broker is the Cayenne, for monitoring via an application on android device using email and password that was created when creating a new project in Cayenne. Monitoring can also be performed by another user without entering your email and password with sharing features dashboards that can be accessed through a web browser on desktop mode. The incoming data will be stored on the database for the purposes of data analysis. The design of the monitoring system and a general overview of soybean seed storage space is shown in Figure 1 .

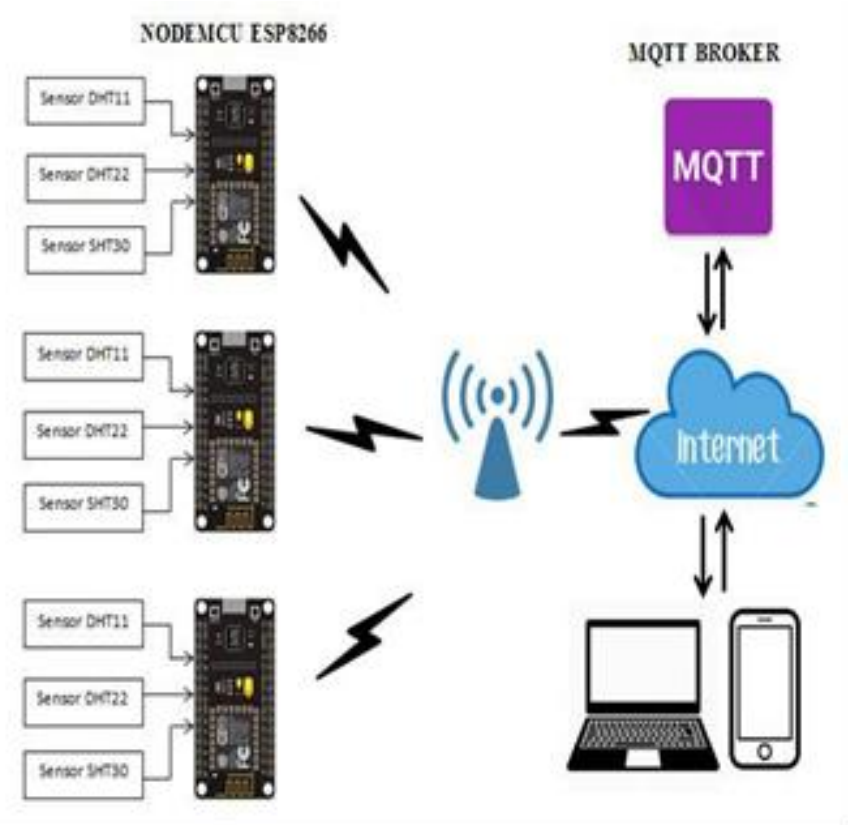

Figure 1. Overview of Monitoring System

In the control system will run after getting commands from the user via android device by logging on the account that was created when creating a new widget. Users who do not have an account, do not have access to the room temperature and humidity control. MQTT broker will send an email notification to the user if the temperature and humidity of the room is detected exceeding the set limit, then the user will perform air-conditioning control system through the application of the Cayenne as MQTT broker on android device. The control system used is a control commands sent to remote air conditioning via android smartphone. The design and general description of the soybean seed storage room controlling system shown in Figure 2.

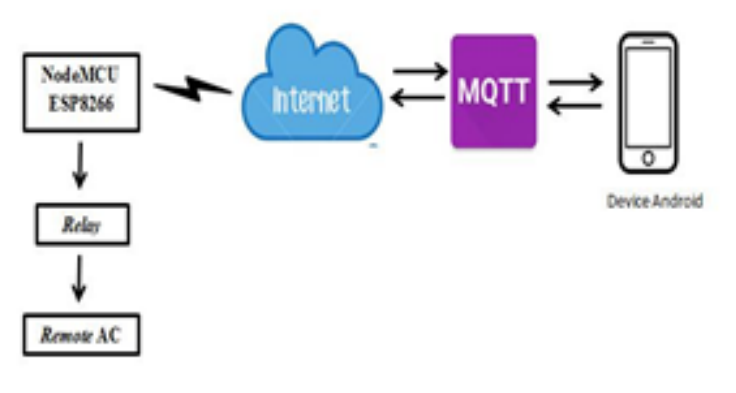

Figure 2. Diagram Control System Overview

The system is designed with a highly efficient. The creation of this system is divided into two parts, the manufacture of hardware and software.

\section{A. Hardware}

This study uses NodeMCU ESP8266 as a data processor that is equipped with a module Wi-Fi $802.11 \mathrm{~b} / \mathrm{g} / \mathrm{n}$, so it can be directly used to transmit wireless data. NodeMCU ESP8266 works at a resolution of 32 bits. In this paper, conditions of temperature and humidity of the room are sampled by sensors DHT11, DHT22, and SHT30. All the 
sensor readings are compared to determine the average conditions of temperature and humidity of the room. NodeMCU and sensors work at a voltage of 3.3 volts. The sensor output data owned by DHT11 sensor, DHT22, and SHT30 is in a digital format, so it does not need the data conversion process measurement of temperature and humidity. Control node odule consists of a NodeMCU ESP8266, 3 pieces of relay, AC (air conditioner) Panasonic remote eqipped with 2 battery AAA, power switcher 5 Volts 3 Ampere for relay, and power adapter 5 Volts 1 Ampere for NodeMCU ESP8266.

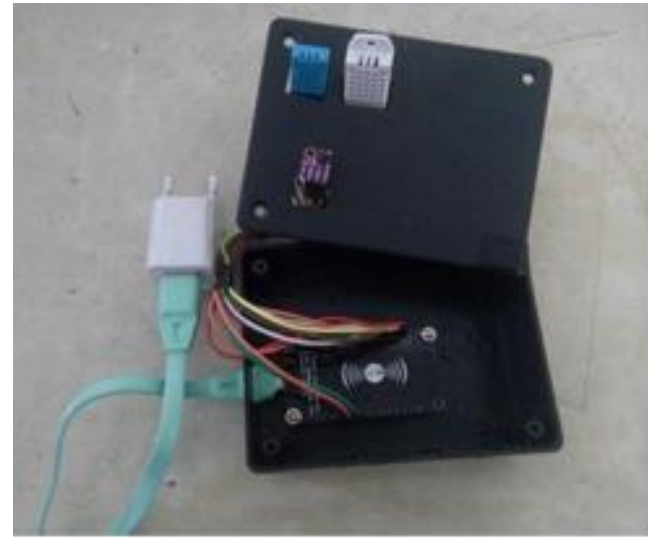

Figure 3. Sensor Node Module

B. Software

A sensor node configured so that the program can work and generate sensor data, using the Arduino IDE software to upload the program into NodeMCU ESP8266. Upload program to NodeMCU ESP8266 with Arduino IDE that has been installed library NodeMCU ESP8266 version 1, DHT11, DHT22, and SHT30 and Cayenne MQTT. The system configuration is divided into monitoring and controlling configuration. Flowchart of the monitoring configuration program can be seen in Figure 4.

NodeMCU monitoring program put ESP8266 to run the monitoring system of soybean seed storage space. The program uses the Arduino IDE software to begin initialization sensor type used, the DHT11, DHT22, and SHT30 and pin sensors connected to NodeMCU ESP866, then connect NodeMCU ESP8266 with access point device that is used as an internet access to connect with MQTT broker. Initialization client ID is used for monitoring systems that have been registered in MQTT broker. Sensors perform readings of temperature and humidity environment which is then sent by NodeMCU ESP8266 towards MQTT broker via the Internet.

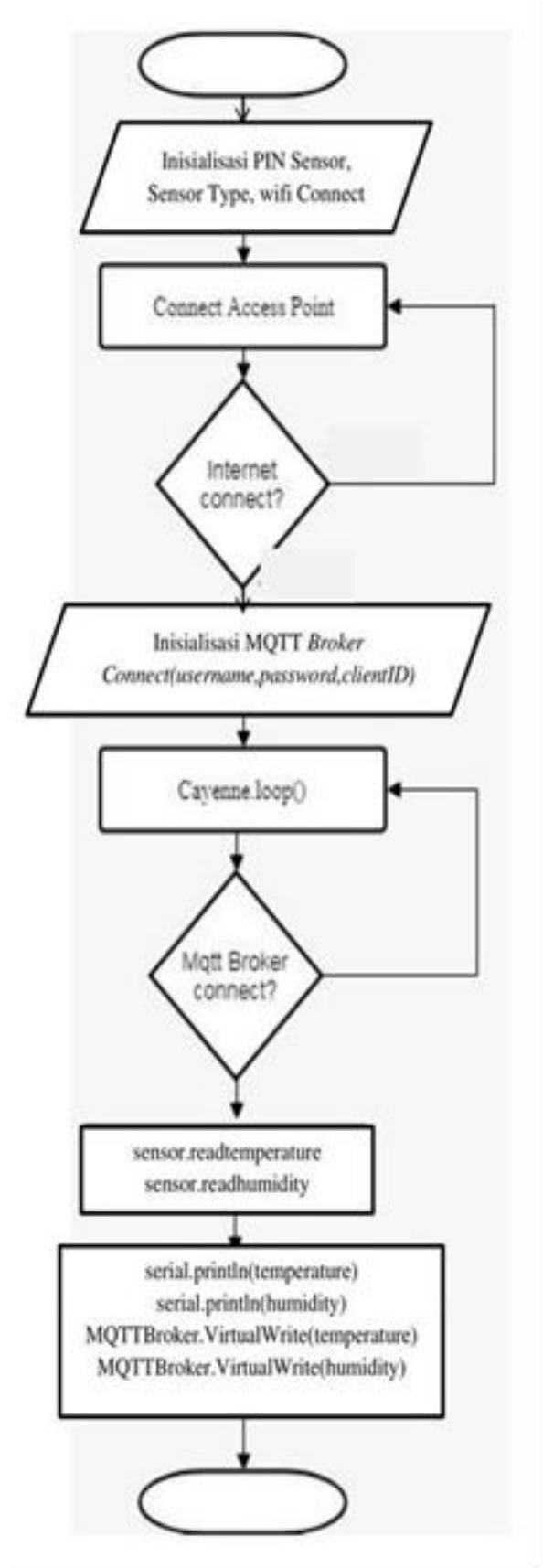

Figure 4. Monitoring Program Flowchart

Control program in Figure 5 is inserted into NodeMCU ESP8266 using Arduino IDE software. The program begins with NodeMCU connect with an access point for internet access, then do initialization client ID that was used as the control system. In NodeMCU do initialization channel that is used as a function of the remote button, the channel 3 represents a command relay 1 active as a on/off function, channel 0 represents the command relay 2 active as a function of up temperature, channel 4 represents the command relay 3 active as a down temperature function. 


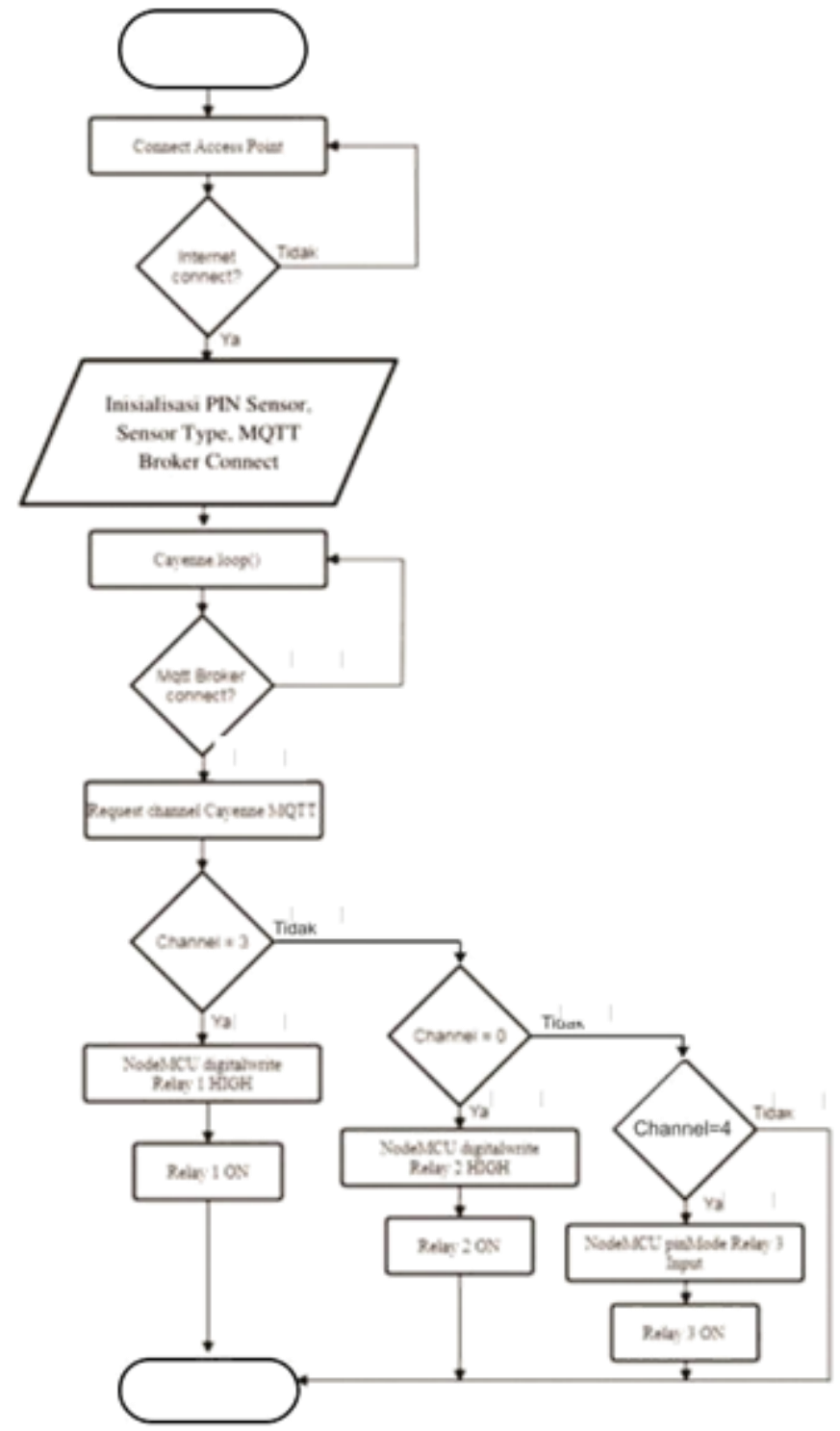

Figure 5. Controlling Program Flowchart

\section{Temperature and Humidity Sensor Data}

Accuracy of the sensor experiments can be seen in a comparison of data from temperature and humidity sensors with measurement of digital measuring devices thermohygrometer. Temperature and humidity sensors have the results of digital data without conversion so that it can be done immediate data analysis. The accuracy of the sensors associated with the sensor performance as it is on the datasheet. Accuracy rates of temperature and humidity sensors can be searched by the formula (1).

Deviation $=$ sensor measurement - thermohygrometer measurement

Dataloss is a the number of missing data at the time of delivery compared with the total amount of data received. Dataloss testing useful to know the quality of data transmission in a system in the category of good or bad. Dataloss value of data transmission temperature and humidity sensors can be searched by the formula (2).
Dataloss calculation results are then compared with the category of quality set by TIPHON.

Table 1. Dataloss Quality Categories Assessment

\begin{tabular}{|c|c|c|}
\hline Category & dataloss & Index \\
\hline Very good & $0-2 \%$ & 4 \\
\hline Good & $3-14 \%$ & 3 \\
\hline Moderate & $15-24 \%$ & 2 \\
\hline Bad & $>24 \%$ & 1 \\
\hline
\end{tabular}

Source: TIPHON

\section{RESULTS AND ANALYSIS}

The study looked at how the data generated by the temperature and humidity sensors to the monitoring system of soybean seed storage room. Data from time to time can be viewed live and stored on the database application for the Cayenne were analyzed and shaped graph. The first experiment was to determine the accuracy of the sensor value at each node that has been installed with DHT11, DHT22, and SHT30. The results of the measurement accuracy of the temperature sensor can be seen in the chart Figure 6.
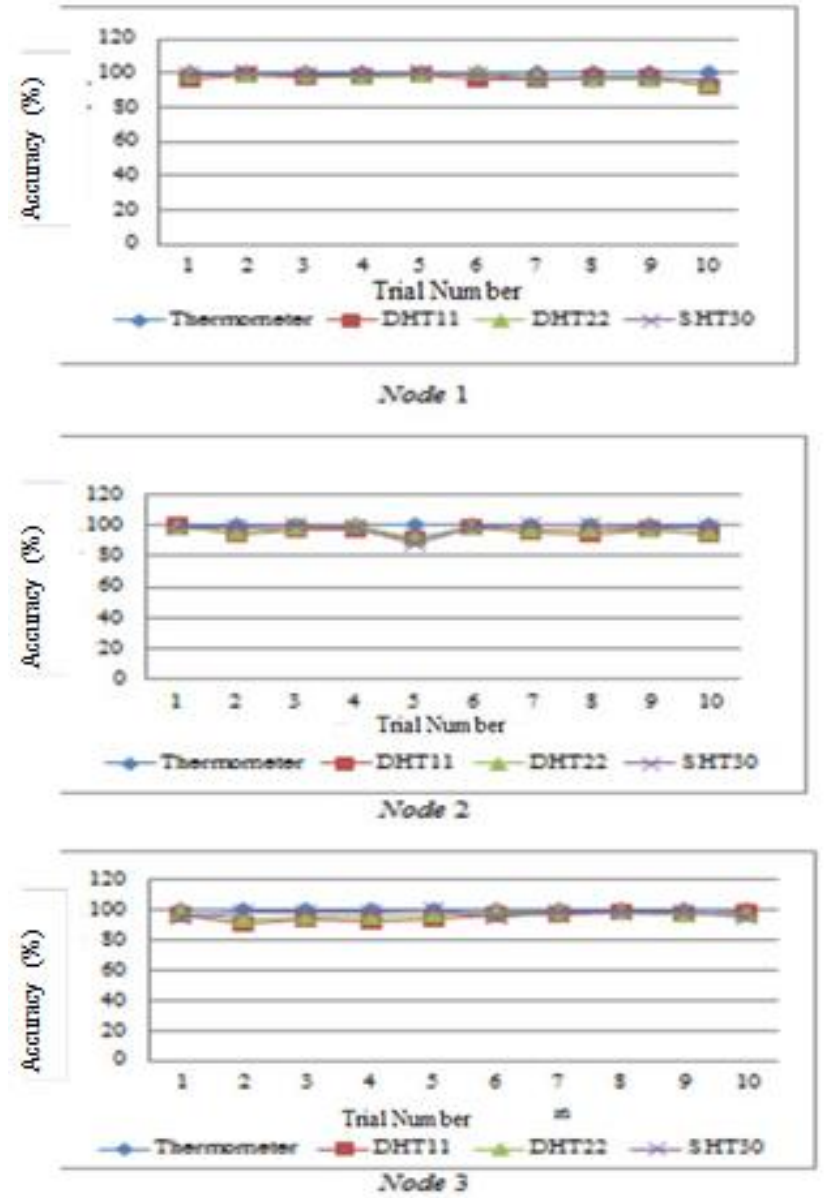

Figure 6. Graphic of Temperature Sensor Accuracy DHT11, DHT22, SHT30 
Based on the measurement accuracy of the temperature that is shown in figure 6, it can be seen that all the sensor has good accuracy value. SHT30 has the highest average value temperature accuracy than sensor DHT11 and DHT22 for all three sensor nodes. The average value for SHT30 temperature accuracy percentage is $98.21 \%$, for the sensor DHT22 is $97.4 \%$ and \%, for the sensor DHT11 $96.22 \%$.

The results of humidity measurement accuracy using sensors DHT11, DHT22, and SHT30 summarized in the chart Figure 7 for each sensor node. Based on the measurement accuracy shown in Figure 7, it can be seen that all the sensor has good accuracy value. DHT22 has the highest average value of the humidity accuracy compared with DHT11 and SHT30 sensors for all three sensor nodes. The average value of humidity for DHT22 accuracy percentage is $95.74 \%$, for the sensor DHT11 of $90.22 \%$, and for SHT30 amounted to $94.37 \%$.

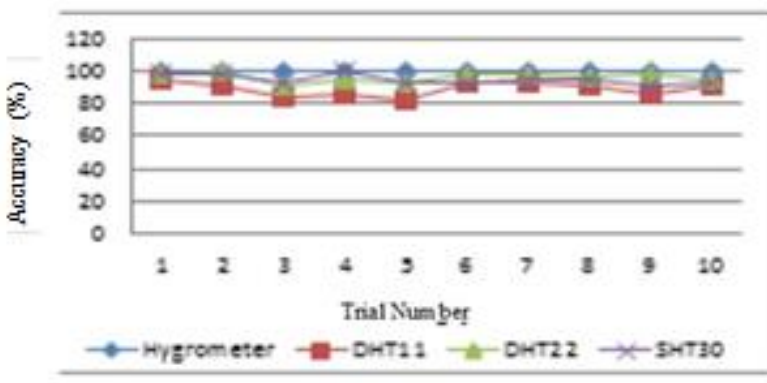

Node 1

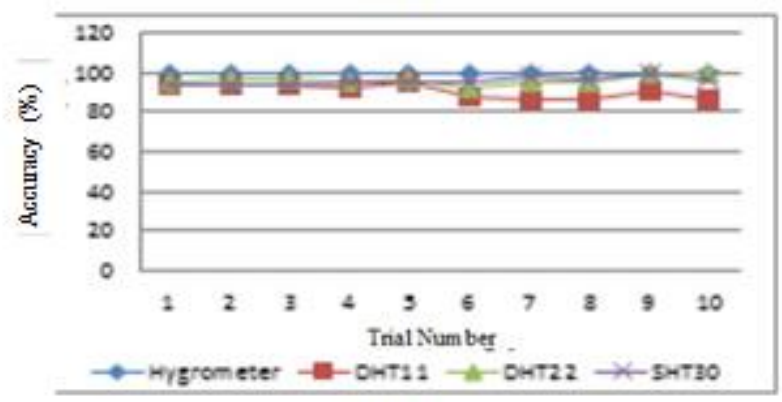

Node 2

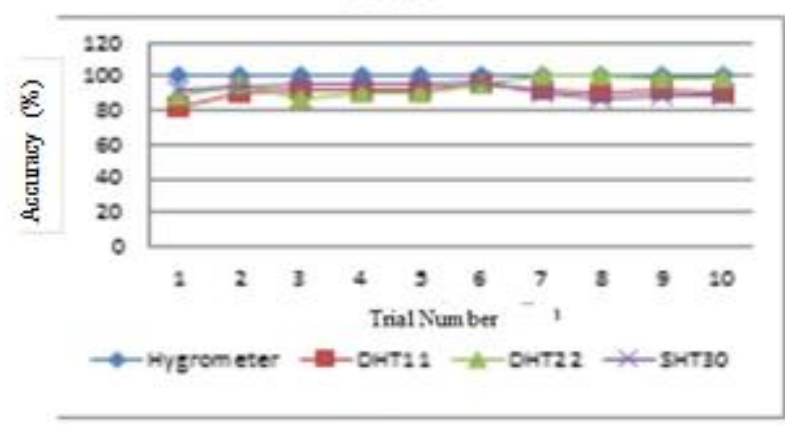

Node 3

Figure 7. Graphic of Humidity Sensor Accuracy DHT11, DHT22, SHT30

The next test is to take the data sampling for 30 minutes to determine the quality of the delivery dataloss to the sensor node database. Results of testing and measurement dataloss of each node can be seen in Table 2 , Table 3 and Table 4.

Table 2. Results of Testing Dataloss Node 1

\begin{tabular}{|c|c|c|c|}
\hline Time & Sent Data & Received Data & Dataloss (\%) \\
\hline 10 minutes & 18 & 17 & 5.55 \\
\hline 20 minutes & 36 & 35 & 2.77 \\
\hline 30 minutes & 54 & 53 & 1.85 \\
\hline \multicolumn{3}{|c|}{ Average } & 3.39 \\
\hline
\end{tabular}

Table 3. Results of Testing Dataloss Node 2

\begin{tabular}{|c|c|c|c|}
\hline Time & Sent Data & Received Data & Dataloss(\%) \\
\hline 10 minutes & 17 & 16 & 5.88 \\
\hline 20 minutes & 34 & 32 & 5.88 \\
\hline 30 minutes & 81 & 80 & 1.23 \\
\hline \multicolumn{3}{|c|}{ Average } & 4.33 \\
\hline
\end{tabular}

Table 4. Results of Testing Dataloss Node 3

\begin{tabular}{|c|c|c|c|}
\hline Time & Sent Data & Received Data & Dataloss (\%) \\
\hline 10 minutes & 19 & 18 & 5.26 \\
\hline 20 minutes & 38 & 37 & 2,63 \\
\hline 30 minutes & 57 & 56 & 1.75 \\
\hline \multicolumn{3}{|c|}{ Average } & 3.22 \\
\hline
\end{tabular}

By the standards TIPHON (Telecommunication Harmonizition Over Internet Protocols Network) dataloss above has a good test results in both categories. Parameters of dataloss excellent, good, average, and poor can be seen in Table 1.

Extensive system testing performed on a different room with air conditioning capacity utilization and the same settings for each room. In the room that had a larger area requires a longer time to cool the room with the same air conditioning settings. These circumstances can be shown on the measurement results of sensors in room 1 with an area of $52.2 \mathrm{~m}^{2}$ and the $2^{\text {nd }}$ room of $36 \mathrm{~m}^{2}$ which has 2 pieces of Panasonic air conditioner CS-PC18MKF with the temperature setting on the remote $20^{\circ}$ Celsius with cool and a maximum fan mode for one hour.

Table 5. Capacity Requirements Table AC

\begin{tabular}{|c|c|}
\hline $\begin{array}{c}\text { Room Area } \\
\text { (square feet) }\end{array}$ & $\begin{array}{c}\text { AC Capacity (BTU / } \\
\text { hour) }\end{array}$ \\
\hline $100-150$ & 5000 \\
\hline $150-250$ & 6000 \\
\hline $250-300$ & 7000 \\
\hline $300-350$ & 8000 \\
\hline $350-400$ & 9000 \\
\hline $400-450$ & 10000 \\
\hline $450-550$ & 12000 \\
\hline $550-700$ & 14000 \\
\hline $700-1000$ & 18000 \\
\hline $1000-1200$ & 21000 \\
\hline $1200-1400$ & 23000 \\
\hline $1400-1500$ & 24000 \\
\hline
\end{tabular}

Source: Energy Star

Each AC has a generating capacity to reduces heat or cool the room with a wide and specific conditions for one hour expressed in BTU / hour. AC capacity needed can be searched by area of the room is used. Based on $\mathrm{AC}$ 
specifications Panasonic CS-PC18MKF, the capacity is $18,000 \mathrm{BTU} / \mathrm{h}$. So if there are two air conditioning in a room it is equivalent to the capacity of $36,000 \mathrm{BTU} / \mathrm{h}$. The area of Laboratory Room 1/01 (room 1) is $52.5 \mathrm{~m}^{2}$ (560 square feet), when viewed from the standards issued by the Energy Star (an international standard for the energy efficiency of products from the United States) in Table 5, the AC capacity needed that is $14,000 \mathrm{BTU}$

/ h. The area of Laboratory Room 1/02 (room 2) is $36 \mathrm{~m}^{2}$ (387 square feet), the air conditioning capacity required is 9,000 BTU / h. From the results it can be seen that the first room requires greater air conditioning capacity compared with the second room, so that the temperature conditioning by the air conditioner can work faster in room 2 (East Laboratories 1/02) compared with the first room (East Laboratorium 1/01). Comparison of cooling conditions on Room 1 and Room 2 can be seen in Figure 8.
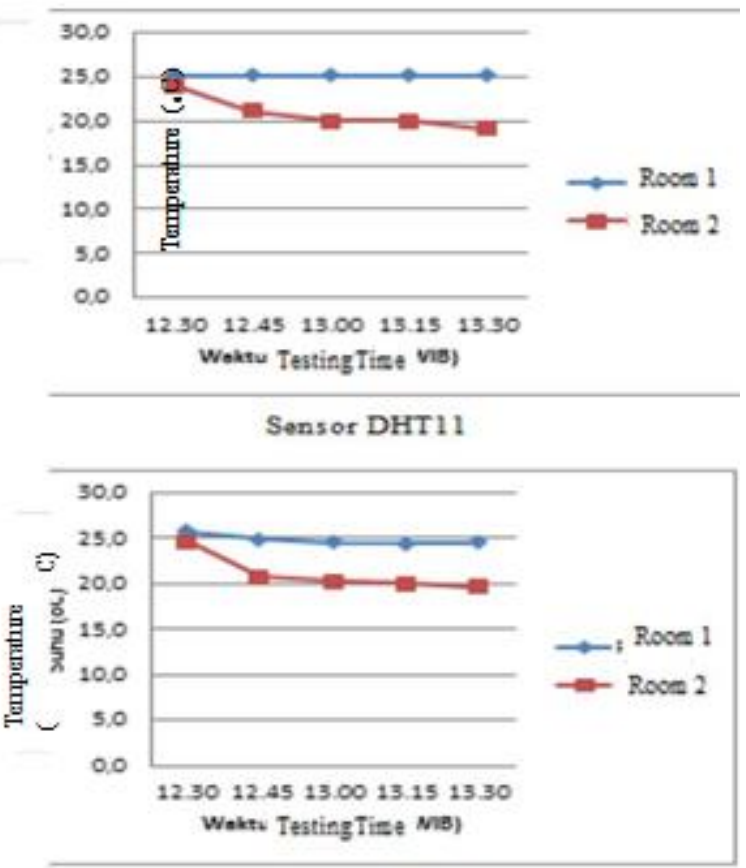

Sensor DHT22

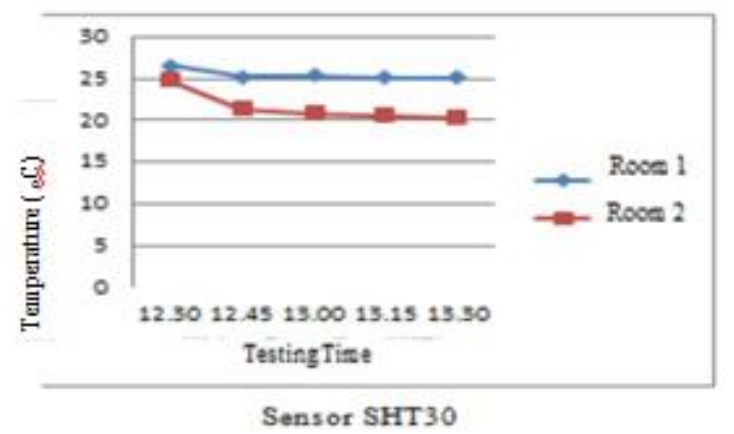

Figure 8. Comparison Values Graphs of Room 1 and 2 with AC Temperature Setting $20^{\circ}$ Celsius

Based on the results of the testing that has been done, it can be seen that the value of the temperature in the room 2 more quickly decreased compared to room number 1 . Within one hour at room temperature 2 has reached $20^{\circ}$ Celsius in accordance with pre-arranged by the remote air conditioning, while the value of humidity not too much changed from the initial conditions before the air conditioning is turned on.

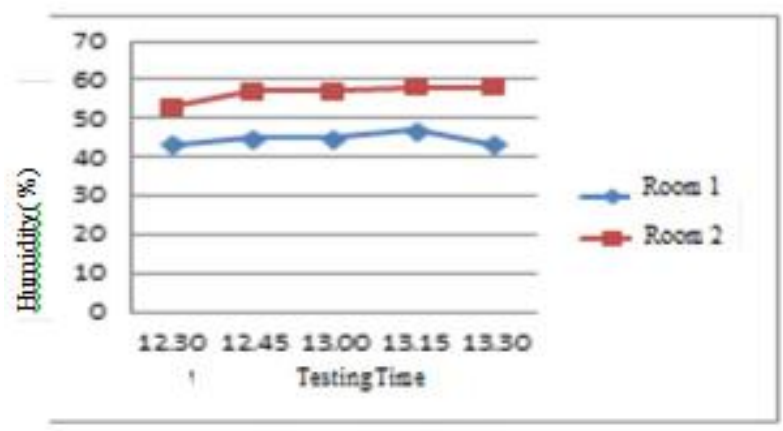

Sensor DHT11

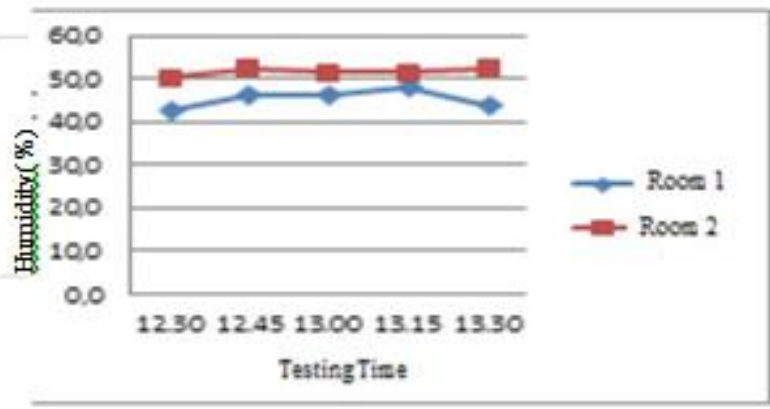

Sens or DHT22

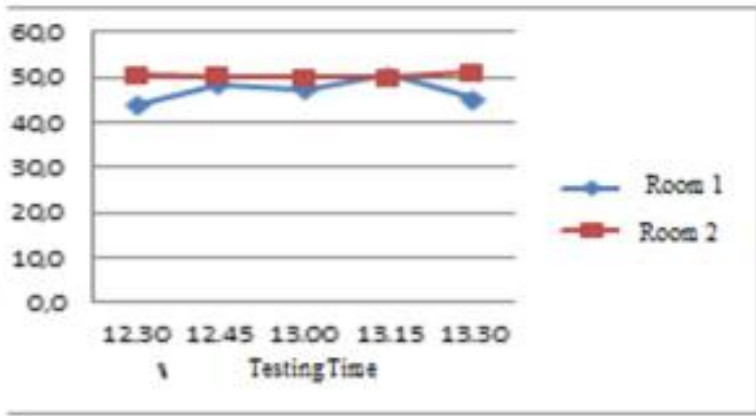

Sensor SHT30

Figure 9. Comparison Values Graphs of Room 1 and 2 with AC Humidity Setting $20^{\circ}$ Celsius

The next test performed was on the room with the same settings AC condition of each test but with a different number of people in the room. In this test, the air conditioner set as $20^{\circ}$ Celsius temperature with cool mode and maximum fan. Tests carried out for 2 hours in the same room, where on the first day there were six people in the room, the second day were 3 people, and the third day the room was made empty. Position of the sensor nodes are also the same 4 meters in front of the air conditioner, the sensor nodes have been installed with sensors DHT11, DHT22, and SHT30 to read the conditions of temperature and humidity of the room.

From the test result with the increasing numbers of people who were in the room cause an increase in the average temperature of the room. This is because the number of people using the room also can add the hot air which is 
inside the room. AC (air conditioner) works by removing the hot air that is inside the room and replacing it with cooler air. So with more heat that must be removed then the air conditioner will work more hours for cooling the room, causing the increase in average temperature of the room with the more number of people who were indoors. The results of the temperature measurement by the sensor can be seen in Figure 10.

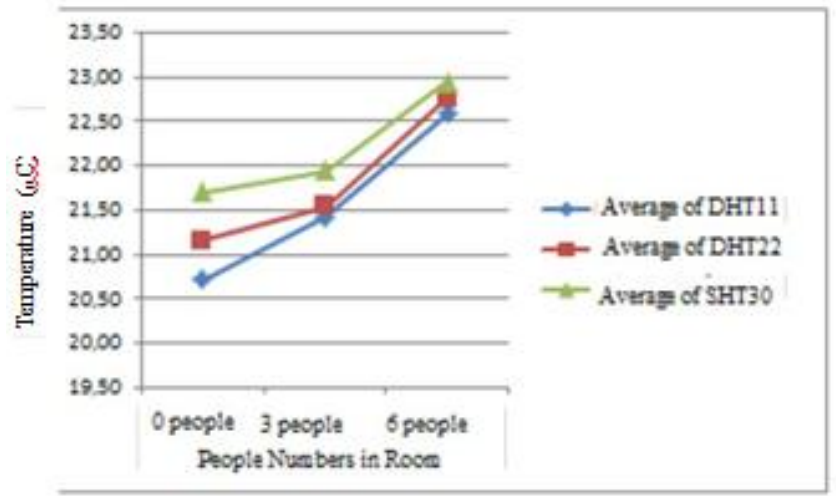

Figure 10. Graphic of RoomTemperature Value with AC Setting $20^{\circ}$ Celsius

The results of humidity measurement has the result that varies inversely with temperature measurement results, in which increasing numbers of people in the room to make the value of humidity has lowered as shown in Figure 11. The humidity here is the relative humidity $(\mathrm{RH})$, which describes the amount of water vapor contained in the mixture air water in the gas phase. The higher temperatures makes the conditions of water vapor contained in the air is getting little or RH values will be lower.

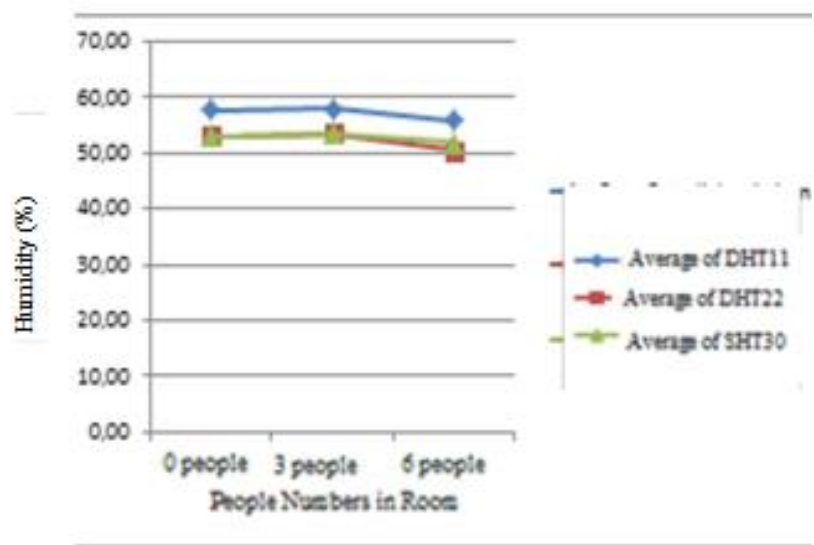

Figure 11. Graphic Value Room Temperature Setting AC $20^{\circ} \mathrm{C}$

\section{CONCLUSIONS AND RECOMMENDATIONS}

From the experimental results and the manufacture of systems in this study can be taken some conclusions as follows:

1. SHT30 sensors work best in the measurement of temperature with smallest average error is $0,43^{\circ} \mathrm{C}$ and has the best accuracy of the temperature measurement with $98.21 \%$ compared to DHT11 and DHT22.
2. DHT22 sensors work best in indoor humidity measurements with average smallest error of $2.1 \%$, and best accuracy of humidity measurement with $95.74 \%$ compared to DHT11 and SHT30.

3. Delivery of sensor data to the database has good quality dataloss that is $3.39 \%$ for node $1,4.33 \%$ for node 2 , and $3.22 \%$ for the node 3 in the delivery time for 30 minutes.

4. AC (air conditioner) has a standard working capacity in units of BTU / $h$ are used to determine the need for air conditioning to a room is calculated from the area of the room is used.

5. The number of people in a room affect the value of the temperature and humidity of the room. The more the number of people in a room to make the value the higher temperatures and lower humidity.

In the data analysis study temperature and humidity sensors in this soybean seed storage space, so that the system becomes more leverage then given suggestions as follows:

1. Adding control functions for the humidity of the room, because the AC (air conditioner) is more effective to regulate and control the temperature of the room.

2. Add notifications to the control system in forms other than email, more can be known directly by the user.

\section{BIBLIOGRAPHY}

[1]. Andriyanto, I., Dwiyatno, S., Komputer SistemTeknologi, F., Serang, U., Kota, R., \& Banten, S. (2015). Rancang Bangun Alat Ukur Temperatur Suhu Perangkat Server Menggunakan Sensor LM35 Bebasis SMS Gateway, 2(1).

[2]. Atmoko, R. A. (2013). Sistem Monitoring dan Pengendalian Suhu dan Kelembaban Ruang pada Rumah Walet Berbasis Android, Web , dan SMS, 283-290. Budioko, T., \& Jurusan Teknik Komputer STMIK AKAKOM YOGYAKARTA. (2016). Sistem Monitoring Suhu Jarak Jauh Berbasis Internet Of Things Menggunakan Protokol MQTT, 353-358.

[3]. Danapriatna, N. (2002). Pengaruh Penyimpanan Terhadap Viabilitas Benih Kedelai. Pengaruh Penyimpanan Terhadap Viabilitas Benih Kedelai, 2, 178-187

[4]. ETSI. (1999). Telecommunications and Internet Protocol Harmonization Over Networks (TIPHON); General aspects of Quality of Service (QoS), 1, 1-37.

[5]. Keyur K Patel1, S. M. P. (2016). Internet of Things-IOT: Definition , Characteristics , Architecture, Enabling Technologies, Application \& Future Challenges, 6(5).

[6]. Kurniawan, A. (2016). Kelembaban Udara Ruangan Berbasis Arduino UNO (October).

[7]. Purwanti, S. (2004). Study of Storage Temperature on the Quality of Black and Yellow Soybean Seed. Ilmu Pertanian, 11(1), 22-31

[8]. Rahmad, Y. (n.d.). Analisa Kinerja Sensor Suhu NTC dan LM35 Dalam Sistem Pendeteksian Suhu Ruangan Berbasis Mikrokontroler AVR ATmega 16, 38-42. 
[9]. Saptadi, A. H., \& Sekolah Tinggi Teknologi Telematika Telkom Purwokerto. (n.d.). Perbandingan Akurasi Pengukuran Suhu dan Kelembaban Antara Sensor DHT11 dan DHT22.

[10]. Sasono, S. H. W., Akrom, R. Al, \& S, R. M. (2015). Optimalisasi Smartphone Untuk Kontrol Dan Monitor Air Conditioner Pada Shelter Starone Semarang, 13, 19-24.

[11]. Shita, R. T., \& Hin, L. L. (2017). Sistem Monitoring Dan Controlling Suhu Dengan Mikrocontroller Berbasis PC dan SMS pada Data Center PT . MNC MEDIA, 9(2), 72-78.

[12]. Statistik, B. P., \& Perdagangan. (2017). Buletin Statistik Perdagangan Luar Negeri, (April).

[13]. Statistik, B. P., \& Perdagangan. (2017). Buletin Statistik Perdagangan Luar Negeri, (March).

[14]. Surur, M., Pramono, S., Wahyudi, E., \& Sekolah Tinggi Teknologi Telematika Telkom Purwokerto. (2015). Sensor Suhu LM35.

[15]. Wicaksono, H., \& Teknik Elektro - Universitas Kristen Petra (n.d.). Relay - Prinsip dan Aplikasi, 1-12. 